\title{
Zur «innern Antisepsis».
}

Von

Dr. H. Bechhold, Mitglied des Instituts.

(Aus dem Königl. Institut für experimentelle Therapie zu Frankfurt a. M., Direktor: Geh. Med.-Rat Prof. Dr. Paul Ehrlich.)

(Der Redaktion zugegangen am 22. Mai 1907.)

In einer im vorigen Jahr erschienenen Arbeit ${ }^{1}$ ) war eine Anzahl neuer Desinfektionsmittel beschrieben worden, die auf eine Reihe von pathogenen Bakterien eine eminente Desinfektions- . kraft ausüben. Es waren darunter solche, die noch in einer Verdünnung von über einer halben Million Bouillonkulturen von Diphtheriebazillen in der Entwicklung hemmten. Diese Substanzen hatten gleichzeitig den Vorzug, praktisch sehr wenig giftig zu sein, so daß es möglich war, dem Tierkörper ohne Schaden Dosen einzuverleiben, von denen schon weniger als der hundertste Teil genügt haben würde, die Bakterien in vitro in der Weiterentwicklung zu hemmen, bezw. in 24 Stunden sogar abzutöten. Dies reizte natürlich sehr, auch Desinfektionsversuche im 'lierkörper vorzunehmen, d. h. z. B. mit Diphtheriebazillen infizierte Tiere durch Einspritzung dieser Desinfizientia zu desinfizieren, also zu heilen. Merkwürdigerweise blieb jeder Erfolg aus und es zeigte sich auch, daß, wenn man die betreffenden Bakterien in Serum statt in Bouillon züchtete, jene Desinfektionsmittel in ihrer Wirkung außerordentlich geschwächt wurden. Während z. B. Tetrachlor-o-biphenol (von Diels) noch in einer Verdünnung von 1:320000 jede Entwicklung von Diphtheriebazillen in Bouillonkultur hinderte, entwickelten sich in einer

1) Beziehungen zwischen chemischer Konstitution und Desinfektionswirkung von Dr. H. Bechhold und Geh. Med.-Rat Prof. Dr. Paul Ehrlich (Diese Zeitschrift, Bd. XLVII, S. 173-199).

Hoppe-Seyler's Zeitschrift f. physiol. Chemie. LII. 
Serumkultur bei Verdünnung des genannten Desinfiziens auf nur 1: 10000 immer noch vereinzelte Kolonien. ${ }^{1}$ ) Man konnte nun im Zweifel sein, ob lediglich die viel günstigeren Lebensbedingungen der Bakterien in dem dem lebenden Organismus entnommenen Serum dies Resultat zur Folge hatten, oder ob chemische bezw. physikalisch-chemische Gründe dies bedingten.

Inzwischen ist es mir gelungen, eine Methode auszuarbeiten, welche die Beantwortung dieser Frage gestattet.

Auf der Versammlung Deutscher Naturforscher und Ärzte (Stuttgart 1906) berichtete ich, daß es gelingt, Kolloide von ihrem Lösungsmittel zu trennen, indem man sie durch Gallerten filtriert. Durch Wahl von Gallerten verschiedener Konzentration hat man es in der Hand, mehr oder minder dichte Filter herzustellen. Die ausführliche Beschreibung dieser Filter, ihrer Anfertigung, Benutzung und der bisher damit erzielten Resultate wird demnächst in der «Zeitschrift für physikalische Chemie» erscheinen. Hier will ich nur die Ergebnisse mitteilen, welche sich auf die Desinfektionsversuche in Gegenwart von Serum beziehen. Die erwähnten Filter gestatten nämlich, Serum derart zu filtrieren, daß nur die in der Flüssigkeit gelösten krystalloiden Stoffe das Filter passieren, während die Proteine vollkommen zurückgehalten werden.

Ich habe nun vermittelst dieser Methode geprüft, ob vielleicht die festen Bestandteile des Serum, das Albumin, Globulin usw., das Desinfiziens binden, ob also vielleicht im Serum nur geringe Mengen Desinfiziens disponibel sind, so gering, daß sie den Bakterien nicht schaden können. Zu dem Zweck stellte ich Serumlösung her, welche einen Gehalt von $1 \%$ Tetrachlor-o-biphenol enthielt, und filtrierte diese durch ein Filter, welches die Eiweißkörper vollkommen zurückhielt, während es das Tetrachlor-o-biphenol passieren ließ. Zur Kontrolle

1) Busk (Biochem. Zeitschrift, Bd. I, S. 424-444) kam bei seinen photobiologischen Studien, unabhängig von uns, zu dem gleichen Resultat, indem er zeigte, daß ein Zusatz von Serum die toxische Wirkung einer großen Zahl sensibilisierender, wie nicht sensibilisierender, verschiedenen chemischen Gruppen entnommener Stoffe gegenüber Paramäcien verringert resp. aufhebt. 
wurde eine $1 \%$ ige Tetrachlor-o-biphenollösung vorher durch das gleiche Filter filtriert.

A. Wässerige Lösung des Tetrachlor-o-biphenols.

$1 \mathrm{~g}$ Tetrachlor-o-biphenol wurde in der geringstmöglichen Menge $\mathrm{NaOH}$ gelöst und mit Wasser auf $100 \mathrm{ccm}$ verdünnt. Diese Lösung wurde bei 1 Atmosphäre durch ein $5 \% \mathrm{v}$ (H $4 \%$ v) Filter ${ }^{1}$ ) filtriert, die ersten $20 \mathrm{ccm}$ Filtrat wieder in den Trichter zurückgegossen und dann $50 \mathrm{ccm}$ filtriert. Im Filtrat wurde das Tetrachlor-o-biphenol durch $\mathrm{HCl}$ gefällt, ausgewaschen und getrocknet gewogen. Die $50 \mathrm{ccm}$ enthielten $0,39 \mathrm{~g}$ Tetrachlor-o-biphenol statt $0,5 \mathrm{~g}$. Es war somit im Filtrat, offenbar durch Absorption im Filter, ein Verlust von $22 \%$ eingetreten.

B. Serumlösung des Tetrachlor-o-biphenols.

$1 \mathrm{~g}$ Tetrachlor-o-biphenol wurde in der geringstmöglichen Menge $\mathrm{NaOH}$ gelöst und mit Vollserum (Ochsenserum) auf $100 \mathrm{ccm}$ verdünnt. Diese Lösung wurde dürch das oben bereits benutzte und mit wenig Wasser abgespülte Filter filtriert. Die ersten $20 \mathrm{ccm}$ Filtrat wurden wieder in den Trichter zurückgegossen, dann $20 \mathrm{~cm}$ filtriert. Im Filtrat wurde das Tetrachlor-o-biphenol wie oben bestimmt. Die $20 \mathrm{ccm}$ enthielten $0,025 \mathrm{~g}$ Tetrachlor-o-biphenol statt $0,2 \mathrm{~g}$. Es war somit durch Bindung von den festen Serumbestandteilen ein Verlust von $87,5 \%$ eingetreten. Die Zahl stellt sich vielleicht noch etwas höher, da ja das Filter von der vorherigen wässerigen Filtration noch etwas Tetrachlor-o-biphenol abgeben mochte.

Es war somit in dem Serum mit einem Gehalt von 1\% Tetrachlor-o-biphenol in Wirklichkeit nur eine 1\%oige Lösung für die Desinfektion disponibel. Da nun bei allen Absorptionen die Kurve derart verläuft, daß bei gleichbleibender Menge des Absorbens und abnehmender Menge der absorbierten Substanz die absolute absorbierte Menge zwar ab, die relativ absorbierte Menge aber zunimmt, so kann es kommen, daß bereits in einem

1) Diese Zahlen charakterisieren die Filterdichte; ihre Bedeutung wird eingehend in genanntem Aufsatz in der Zeitschrift für physikalische Chemie erläutert. 
Vollserum, welchem 1 : 10000 Desinfiziens zugesetzt ist, praktisch die gesamte Menge des Desinfiziens vom Serum mit Beschlag belegt ist. Es stimmt dies mit den eingangs gefundenen Ergebnissen unserer früheren Publikation.

$\mathrm{Ob}$ die Bindung als chemische oder nur als physikalische Adsorption zu bezeichnen ist, muß zunächst offen bleiben. Ein dahingehender Versuch gab keine eindeutigen Resultate. Zur definitiven Lösung bedürfte es einer großen Folge von Versuchen bei verschiedenen Konzentrationen; die so erzielte Kurve würde Auskunft geben.

Das aber ist sicher, daß in erster Linie chemische oder physikalisch-chemische Ursachen, nämlich die Bindung des Desinfiziens durch das Blutserum, die Herabsetzung der Desinfektionswirkung im Organismus bedingten, daß rein biologische Begünstigung des Bakterienwachstums durch bessere Lebensbedingungen, wenn überhaupt vorhanden, nur eine nebensächliche Rolle spielt. 